\title{
Effect of Credit and Training Facilitation on Financial Control Practices in Women-Owned Enterprises in Nakuru County
}

\author{
Chebet Joan Kirui \\ Kabarak University
}

\begin{abstract}
Women entrepreneurship could be an effective strategy for poverty reduction. However, women entrepreneurs, especially in developing countries, have limited access to loans for their entrepreneurial ventures and, as such, have low business performance than their male counterparts, whereas the rate of their participation in the informal sector of the economy is higher than males, and microfinance could have positive effect on enterprise performance. More often than not, small businesses fail to keep good records of their financial transactions, and this may limit their access to credit interventions by their financial partners. Consequently, microfinance institutions have been providing assistance to women entrepreneurs in the form of training and credit for their businesses. What remains to be known was the extent to which the training component of the intervention was impacting financial control practices of the women-owned enterprises. Therefore, the present study sought to establish the effect of credit and training facilitation on financial control practices in women-owned enterprises in Nakuru County. The study used survey research design targeting women enterpreneurs in the area who were working with SMEP microfinance. Random sampling design was adopted targeting 310 women using questionnaires. Data was analyzed using both descriptive and inferential statistics. The findings reveal that that there was a significant improvement in budgeting and bookkeeping after receiving training and credit from the organization. This led to the finding that the training and credit intervention was making a positive impact on the performance of women-operated businesses in the area. However, there was need to focus more on the profit and loss aspect of training as this area was underperforming. It is recommended that training frequency need to be increased as majority of the women entrepreneurs interviewed in this study had only trained for a maximum of two sessions and obtained credit twice from the training organization.
\end{abstract}

Keywords: Credit and Training, Bookkeeping and Budgeting, Financial Control Practices

\section{Introduction}

As economies open up and become increasingly liberalized, many business opportunities become available by the day thereby attracting more players at all levels of business developments (ILO report to the G20 Leaders' Summit, 2009). This leads to market expansion, increased production, diversity of the product base and import export phenomenon that in many cases flood the markets with inexpensive products. Coupled with this is the fact that many governments like in this case the Kenya government have taken note of the viability of SMEs in the economies and have thrown their weight behind their development by providing enabling legislation, market facilities, financial support through the budgets and also development partners, and other forms of business developments assistance to the entrepreneurs (Republic of Kenya, 2012). EkpeI, Mat, and Razak (2010) pointed out that women play an important role in the economic wellbeing of their families and communities yet certain obstacles such as poverty, unemployment, low household income and societal discriminations common in developing countries have hindered their effective performance of that role. This is the major reason why most of them embark on entrepreneurial activities to support their families. Furthermore, women are the worst hit when poverty rates are high in a country.

Women entrepreneurship could be an effective strategy for poverty reduction. According to Khanka (2010), women constitute almost half the total population in the world and are thus regarded as the better half of the society. They were confined to the four walls of houses, performing household activities in the traditional society. He further noted that in the modern society however, they have come out of the four walls to participate in all sorts of activities including getting into industry and are running their enterprises. However, women entrepreneurs, especially in developing countries, have limited access to loans for their entrepreneurial ventures and, as such, have low business performance than their male counterparts, whereas the rate of their participation in the informal sector of the economy is higher than males, and microfinance could have positive effect on enterprise performance. In addition, for most of the women-owned businesses are confronted by a myriad of challenges for them that cannot be solved using capital adequacy alone. For example, the lack of adequate financial controls is hindering the growth prospects of their businesses as it affects planning and control of finances available to them. Some of these businesses even fail to break-even and wind up prematurely. 
Financial control practice is a core management aspect of any organization that determines their performance in various aspects. Financial control practices have a large bearing on the internal efficiencies of business organizations that could well determine their profitability, growth and sustainability prospects. At the heart of financial control practices is budgeting and bookkeeping. A budget is a document or a collection of documents comprising a detailed description of the expected revenues and expenditures of a given institution, associated with the activities that are planned for achieving specific purposes or goals, within a given period. The budget's purpose can be summarized as assisting systematic planning; quantifying objectives and identifying priorities; coordinating activities and communicating plans within the organization; motivating and increasing the accountability of middle management; authorizing expenditure and activities; controlling, monitoring and analyzing expenditure; and evaluating performance (Kruger 2005; Ntseto, 2009). In business, bookkeeping can be described as the systematic capture and up-to-date maintenance of data relating to financial transactions incurred by the business in the course of its operations. Consequently, effective management of the business' records will allow its owner(s) to have a fair assessment of its health status, such as, profitability, growth, assets and liabilities among other things. Strictly speaking, effective bookkeeping brings the product of the business' economic activities to light (Bhattacharya, 2015). Thus, bookkeeping is a prudent way of gauging the business' performance so as to facilitate planning and control activities.

Budgeting still presents a significant challenge to small businesses, according to Harun et al. (2010), most small businesses require Small Medium Accounting Practices (SMPs) help so they could utilize financial tools such as breakeven point, budgeting, financial ratios, costing analysis which could enable them to track the business performance. This needs to be so as most SMEs owners or operators have non-financial background and lack accounting knowledge. For example, most businesses are capital sensitive and poor capital budgeting could have serious performance outcomes for the businesses. Capital budgeting is meant to achieve the highest profitability and cost effectiveness in different areas of the business. Capital budgeting and the estimation of the cost of capital, that is, the rate of return that a firm needs to earn on its investments to ensure that the minimum requirements of the providers of capital are met are the most important financial decisions facing owners/managers of the small firms. However, for the budgeting process to be effective, the SMEs need more inputs in terms of accounting services to enable them assess their financial strength in order to provide a better understanding of their financial position.

Essentially, SMEs need accounting services and functions so as to enable them have enhanced management control and better decision-making that could help them maximize their efficiencies (Dorasamy et.al, 2010). Moreover, the current accounting software is easy to use and could be adapted to small business operations; this can have a significant impact on the management and overall performance of the businesses (Ismail \& Mat Zin, 2009). According to studies by Dyer and Ross (2008) and Kamyabi and Devi (2011), the vast majority of SMEs are inclined to flop due to lack of or inadequate financial planning, marketing knowledge, absence of managerial skills and competency of capabilities. In addition, Dorasamy et al, (2010) and Ismail (2002) point out that poor bookkeeping practices by SMEs owners or managers also impede the accounting process, thereby, denying the business of competent advisory services which could have been derived from their business records. Most of them do not appreciate the usefulness of such data in generating valuable reports for control and decision making purposes (Husin \& Ibrahim, 2013). A study by Peacock (2008) on effects and causes of proprietary company failures in South Australia attributed proprietary company's failures to inadequate or no accounting records. Bwana and Mwakujonga (2013) study of the practice of preparing and using financial information for financial decision-making in SMES in Tanzania found that, most of the SMEs in the country prepared financial information for purposes other than appraising their own performance for the purposes of decision making. Most sought to meet the requirements of financiers, business registration and revenue authorities but not to determine their financial position, performance and growth. Similarly, Dawuda and Azeko (2015) study of SMES in Ghana brought to light issues such as perceived high cost involved in preparing and maintaining proper books of accounts discouraged the SME owners who apparently could not see any value in the financial information in managing their businesses. Moreover, quite a number of the SMEs habitually failed to maintain proper books of accounts in order to evade payment of tax.

Effective financial controls translate to more efficient business operations that also it in a competitive position especially when seeking funding for expansion (Nyakeri, 2012). However, more often than not, small businesses fail to keep good records of their financial transactions, and this may limit their access to credit interventions by their financial partners (Chepkemoi, 2013). Consequently, there is a shift in paradigm where the partnering institutions now provide training in bookkeeping and budgeting as opposed to demanding it from their clients. This is especially important for women-owned enterprises which compared to those of their male counterparts are not technically equipped (Pande et al, 2007). Microfinance institutions have been offering loans to their customers to start or expand their businesses and in Kenya. Some like, the Small and Micro Enterprise Programme (SMEP) have been providing assistance to women entrepreneurs in the form of training and credit for their businesses. What remains to be known was the extent to which the training component of the 
intervention was impacting financial control practices of the women-owned enterprises. Therefore, the present study sought to establish the effect of credit and training facilitation on financial control practices in womenowned enterprises in Nakuru County. Studies done in this area have explored factors influencing bookkeeping practices among SMES and have, consequently, used different methodologies. Moreover, the sampling criteria used in the previous studies permitted the inclusion of all SMEs irrespective of their characteristics. The present study sought to undertake a more in-depth look at the problem at hand using a comparative approach that focused on the same group of women-owned enterprises over a period of time.

\section{Research Methodology}

This was a longitudinal study utilizing a descriptive-comparative research design. This involved studying the performance of women-operated enterprises before and after training and credit was offered. This was compared to determine whether there is a significant difference in the performance of the businesses after the credit and training were offered. The target population was 2064 SMEP's women customers who operate enterprises in Nakuru Municipality and received training and credit. Stratified random sampling was employed to obtain a sample size of 336 respondents. The instruments used in this study were structured questionnaires that were administered twice to the same respondents at different times-over a period of six months. They were researcher administered to avoid respondent bias especially at the follow-up stage. The questionnaires were pretested for validity and reliability where both construct validity and content validity were used to ascertain validity and test-retest method used to determine the reliability of the instruments. A reliability coefficient $\mathrm{R}=$ 0.7643 resulted from the teats which showed that the instruments could be safely administered after some modifications. Data was analyzed descriptively using means to describe the basic features of the data. The data was also subjected to Z-tests draw further meaning from it.

\section{Results and Discussions}

\subsection{Introduction}

Three hundred and thirty six instruments were administered to the respondents and three hundred and ten were returned duly filled and useable for the study purposes. This represented a $92 \%$ response rate which was considered acceptable for the study purposes.

\subsection{Effects of Training in Budgeting and Bookkeeping}

The study sought to determine the extent to which training influenced Budgeting and Bookkeeping of women-owned enterprises in Nakuru Municipality. The results on this are summarized in Table 4.3.

Table 1: Status of Budgeting \& Bookkeeping before \& after Receiving Credit \&Training

\begin{tabular}{|c|c|c|c|c|c|c|c|c|}
\hline \multicolumn{3}{|c|}{ Areas of book keeping and budgeting } & Paired Differences & Std. Error Mean & $95 \%$ Confidence Interval of the Difference & & $\mathrm{t}$ & Sig.(2-tailed) \\
\hline & & & Difference & & & & & \\
\hline & Period & Mean & Mean & & Lower & Upper & & \\
\hline Income & After & 4.34 & & & & & & \\
\hline Anticipated & After & 4.25 & & & & & & \\
\hline expenses & Before & 2.36 & 1.89 & 0.051 & 1.79 & 1.99 & 37.131 & 0.000 \\
\hline Financial & After & 4.23 & & & & & & \\
\hline Petty cash & After & 4.54 & & & & & & \\
\hline book & Before & 2.79 & 1.75 & 0.06 & 1.631 & 1.866 & 29.33 & 0.000 \\
\hline Records of assets \& & After & 4.11 & & & & & & \\
\hline liabilities & Before & 2.24 & 1.87 & 0.057 & 1.762 & 1.987 & 32.73 & 0.000 \\
\hline Profit \& loss & After & 4.12 & & & & & & \\
\hline account & Before & 2.43 & 1.687 & 0.067 & 1.555 & 1.819 & 25.162 & 0.000 \\
\hline
\end{tabular}

The results in Table 1 indicate that prior to training and receiving credit the status of income projections was poor (mean $=2.52)$ as a result of poor anticipation of expenses $($ mean $=2.36)$ or hidden expenses and unrealistic setting of financial goals for the businesses (mean $=2.48$ ). The findings also indicate that the petty cash books were poorly kept (mean $=2.79)$ prior to training and credit and the keeping of records of assets and liabilities was also rated as poor (mean $=2.24$ ) while the entrepreneurs were not also able to rightly appraise their profit and loss accounts (mean = 2.43). However, it is evident from the results that there was a marked improvement in the situation to a good status in terms of income projections $($ mean $=4.34)$ after receiving credit and training as the respondents were now able to correctly anticipate expenses $($ mean $=4.24)$ and realistically set financial goals $($ mean $=4.23$ ). The training received from the organization had also enabled the entrepreneurs to improve their management of their petty cash books (mean $=4.54)$, their management of records of assets and liabilities (mean $=4.11)$ and also their profit and loss accounts $($ mean $=4.12)$. The results 
also suggest that all the differences in the means of the performance of the predictors of this variable both before and after receiving credit and training from the organization lied within the confidence intervals and, therefore, were significant $(\mathrm{p}<0.05)$. These improved responses after receiving credit and training imply that the credit terms offered by SMEP to the women entrepreneurs in the area were manageable and could also mean that the training methods were generally effective.

\subsection{Inferential Statistics}

Z-tests for comparing two related samples were done to evaluate the relationships between the status of the variables both before and receiving training and credit based on their means. The statistic was calculated and used to establish the significance of training and credit on the overall performance of the women owned enterprises. The findings presented in the following subsections.

Table 2: Z-Tests Results on the Status of Bookkeeping and Budgeting

\begin{tabular}{|l|l|l|l|l|l|}
\hline & \multicolumn{2}{|c|}{ Credit } & and training & \\
\hline Apects of Bookkeeping & \multicolumn{2}{|l|}{ Before } & \multicolumn{2}{|c|}{ After } & \\
\hline and Budgeting & Mean & & Mean & z-statistic \\
\hline Income projection & 2.52 & & 4.34 & 17.52 \\
\hline Anticipated expenses & 2.36 & & 4.25 & 18.62 \\
\hline Financial goals & 2.48 & & 4.23 & 16.98 \\
\hline Petty cash book & 2.79 & & 4.54 & 5.575 \\
\hline Records of assets and liabilities & 2.24 & & 4.11 & 14.27 \\
\hline Profit and loss account & 2.43 & & 4.12 & -2.27 \\
\hline
\end{tabular}

The results in Table 2 indicate that budgeting and bookkeeping improved in the businesses as a result of receiving training and credit. The $\mathrm{z}$-tests reveal that $\mathrm{z}>1.960 ; \alpha<.05 ; \mathrm{df}=309 ; \mathrm{p}=0.000$ which shows that bookkeeping was statistically significant to the performance of women owned enterprises in the area. The results also indicate that the z-values for all the means of the indicators of the status of this variable save for the one for profit and loss both before and after the interventions were greater than the critical valuefor a one tailed test leading to the rejection of the null hypothesis. This implied that obtaining training and credit from the organization did improve the women business operators bookkeeping and budgeting skills. This suggests that more training in budgeting and bookkeeping could reduce the underperfomance of the businesses and, therefore, needed to be emphasized as majority of the women enterpreneurs interviewed in this study had only trained for a maximum of two sessions and obtained credit twice from the training organization. However, the findings on the management of profit and loss account $(\mathrm{Z}=-2.27)$ indicate that there was need for more training focus in this area as it appears that the enterpreneurs had not fully grasped the concept. These findings agree with those of Karlan and Valdivia (2006) pointed out that the goal of the business training intervention is two-fold: to improve business outcomes and overall welfare for clients and to improve institutional outcomes for the microfinance institution. In the latter sense, the implication is that the credit risk significantly reduced when dealing with trained clients especially those who knew how to budget and keep their books. It also agrees with Edgcomb (2002) who also found out that training increased the likelihood that individuals reinvested profits in their business by four percentage points.

\section{Conclusions and Recommendations}

Credit and training in budgeting and bookkeeping offered by SMEP resulted in a positive response that could imply that the credit terms offered by SMEP to the women entrepreneurs in the area were manageable and could also mean that the training methods were generally effective. A z-test showed that there was a significant improvement in budgeting and bookkeeping after receiving training and credit from the organization. This led to the finding that the training and credit intervention was making a positive impact on the performance of womenoperated businesses in the area. However, there was need to focus more on the profit and loss aspect of training as this area was underperforming. Therefore, more training in budgeting and bookkeeping could improve the performance of the businesses. Training in budgeting and bookkeeping could significantly reduce the underperfomance of the businesses although the credit terms offered by SMEP to the women entrepreneurs in the area also appeared to be manageable and the training approaches could be generally effective.Hence, based on the results of this study it can be concluded that there was a general improvement on the performance of the businesses as a result of the training. In line with the foregoing findings, it is recommended that training frequency need to be increased as majority of the women entrepreneurs interviewed in this study had only trained for a maximum of two sessions and obtained credit twice from the training organization. This was deemed insufficient. 


\section{References}

[1] Bhattacharya, D., \& Nakama, D.A. (2015). Evolution of Information Security Issues in Small Business. National Cybersecurity Institute Journal, 2(3), 31-44.

[2] Bwana K.M. \& Mwakujonga J. (2013). The Practice of Preparing and Using Financial Information in Financial Decisions: A Survey of SMEs in Tanzania. European Journal of Business and Management 5(9), 161-169.

[3] Chepkemoi, J. (2013). Factors influencing the Financial Sustainability of Selected SMEs in Kenya, Kenya Economic Review, 4, 2429.

[4] Dawuda A. \& Azeko I. (2015). An Assessment of Financial Records Keeping Behavior of Small Scale Businesses in Ghana: A Case Study of Bolgatanga Municipality. International Journal of Finance and Accounting, 4(3): 187-194

[5] Dorasamy, M., Marimuthu, M., Jayabalan, J., Raman, M., \& Kaliannan, M. (2010). Critical factors in outsourcing of accounting functions in Malaysia small medium-sized enterprises (SMEs). Kajian Malaysia, 28 (2)

[6] Dyer, L.M. \& Ross, C.A. (2008). Seeking advice in dynamic and complex business environment: Impact on the success of small firms. Journal of Development Entrepreneurship, 13(2), 133-149.

[7] Edgcomb, E. L. (2002). What makes for effective microenterprise training? Journal of Microfinance, 4, $100-114$.

[8] Ekpel, I., Mat, N. B. and Razak, R. C. (2010). The Effect of Microfinance Factors on Women Entrepreneurs' Performance in Nigeria: A Conceptual Framework. International Journal of Business and Social Science, 1, 255-263.

[9] Husin, M.A.,\& Ibrahim,M.D. (2013). The Role of Accounting Services and Impact on Small Medium Enterprises (SMEs) Performance in Manufacturing Sector from East Coast Region of Malaysia:A Conceptual Paper. The 5th Indonesia International Conference on Innovation, Entrepreneurship, and Small Business (IICIES 2013). Procedia - Social and Behavioral Sciences 115, 54 $-67$

[10] Harun, H., Ishak, I., Sofri, Y., Siti Nabiha, A.K., \& Yuvaraj, G. (2010).Cases of successful Malaysia small and medium enterprises (SMEs): does business advisory services help? Malaysia Accountancy Research and Education (MAREF).

[11] Ismail, N.A., \& Zin, R.M. (2009). Usage of accounting information among Malaysian bumiputra small and medium nonmanufacturing firms. Journal of Enterprise Resouces Planning Studies.

[12] Ismail, N.A., (2002). A framework for the study of accounting information systems in small businesses. Akauntan Nasional $15(5): 32-33$

[13] Kamyabi, Y. \& Devi, S. (2011). Use of profesional accountants' advisory services and its impact on SME performance in an emerging economy : a resource-based view. Journal of Management and Suistainability. Vol.13. No.1. 43-55.

[14] Karlan, D. \& Valdivia, M. (2006). Teaching Entrepreneurship: Impact of Business Training on Microfinance Clients and institutions. Retrieved on April 15, 2013 from http://aida.econ.yale.edu/karlan/papers/TeachingEntrepeneurship.pdf

[15] Khanka, S. S. (2010). Entrepreneurial Development. New Delhi: S. Chand \& Company Ltd Kruger, G.A. (2005), “A Statistician Looks at Inventory Management", Quality Progress, 38, 2, pp.36.

[16] Ntseto, V. E. (2009). A Programme to Facilitate Principals' Financial Management of Public Schools. PhD Dissertation. Bloemfontein, South Africa: University of the Free State.

[17] Nyakeri,M.K. (2012)The Effect Of Financial Management Practices On The Financial Performance Of Small And Medium Enterprises In Kenya. Unpublished MBA Thesis, University of Nairobi

[18] Pande, R., Field, E., Jayachandran, S., Varma, D. and Starr, S. (2007). The Impact of Business Training on Small Business Outcomes. Economic Journal, 117, 1-7.

[19] Peacock, R. W. (2008). Small Business Bankruptcy, Accounting Forum, 1 (3), 51-52.

[20] Republic of Kenya (2012). Economic Survey. Nairobi; Government Printer. 